\title{
Exposure to potentially inappropriate medications in Brazilian elderly outpatients with metabolic diseases
}

\author{
Vanessa dos Santos Martins ${ }^{1}$, Ana Luiza Pereira Moreira Mori², Egidio Lima Dorea ${ }^{2}$, Gelba \\ Almeida Pinto ${ }^{2}$, Mario Hiroyuki Hirata ${ }^{1}$, Felipe Dominguez Crespo Hirata ${ }^{3}$, Rosario Dominguez \\ Crespo Hirata ${ }^{1}$
}

\author{
${ }^{I}$ School of Pharmaceutical Sciences, University of Sao Paulo, Sao Paulo, Brazil, ${ }^{2}$ University Hospital, University of Sao \\ Paulo, Sao Paulo, Brazil, ${ }^{3}$ School of Technology, State Center for Technological Education Paula Souza, São Paulo, Brazil
}

\begin{abstract}
Management of pharmacotherapy in elderly with metabolic diseases is challenging and potentially inappropriate medications (PIMs) are risk factors for drug interactions and adverse events. The exposure to PIMs in elderly outpatients with metabolic diseases and its relationship with polypharmacy and other variables was investigated. PIMs prescribed to 207 elderly patients (aged 60 to 96 years) with metabolic diseases who attended a University Hospital of Sao Paulo city, Brazil, from April/2010 to January/2011, were evaluated. PIMs were detected using both 2003 Beers and 2008 STOPP criteria. The association between PIMs and age, gender and polypharmacy was also examined. 2008 STOPP criteria detected more PIMs (44.4\%) than 2003 Beers criteria $(16.0 \%, \mathrm{p}<0.001)$. Beers detected mainly PIMs antihypertensive (clonidine, 20.0\%; doxazosin, 10.0\%) and antidepressant (fluoxetine, 15.0\%; amitriptyline, 10.0\%) PIMs. Medicines used for cardiovascular (aspirin, 53.7\%) and endocrine system (glibenclamide, 21.3\%) were PIMs more frequently detected by 2008 STOPP. Unlike age and gender, polypharmacy increased the risk of PIMs by both 2003 Beers (OR: 4.0, CI95\%: 1.2-13.8, p<0.031) and 2008 STOPP (OR: 6.8, CI95\%: 3.0-15.3, $\mathrm{p}<0.001$ ). Beers and STOPP criteria are important tools to evaluate the exposure to PIMs, which is strongly associated with polypharmacy in elderly outpatients with metabolic diseases.
\end{abstract}

Uniterms: Potentially inappropriate medications/elderly/effects. Elderly/metabolic diseases/study. Pharmacotherapy/elderly. Beers criteria. STOPP criteria. Polypharmacy.

\section{INTRODUCTION}

The prevalence of metabolic diseases, including diabetes, dyslipidemia, and hypertension, is rapidly increasing worldwide, especially in the older population. Patients with metabolic diseases are treated with antihypertensive, lipid-modifying and anti-diabetic drugs that can cause drug-drug interactions and other drug-related problems. Therefore, management of pharmacotherapy in elderly with metabolic diseases is challenging due to the potential drug-related problems, which increases the risk for adverse events (Zaman Huri, Chai Ling, 2013). Treatment of hypertension with methyldopa and clonidin, for example, and stimulators of insulin production, such as chlorpropamide and glibenclamide, may cause

\footnotetext{
*Correspondence: R. D. C. Hirata. Departamento de Análises Clínicas e Toxicológicas. Faculdade de Ciências Farmacêuticas - USP. Av. Prof. Lineu Prestes 580 B-17 - 05508-000 - São Paulo - SP, Brasil. E-mail: rosariohirata@usp.br
}

bradycardia, orthostatic hypotension and hypoglycemia, increasing the risk of falls in elderly.

Potentially inappropriate medications (PIMs) are commonly found in elderly pharmacotherapy that requires adjustments to overcome the changes in drugs metabolism due to decreased physiological functions, which increase the risk of drug toxicity (O'Connor, Gallagher, O’Mahony, 2012).

Pharmacotherapy for the elderly has specific requirements owing to the presence of comorbidities, drug interactions and other factors that lead to an increased risk of adverse drug reactions (ADRs). Therefore, the detection of PIMs in elderly patients could reduce the risk of ADRs and provide a safer and more effective pharmacotherapy (Pretorius et al., 2013).

Several tools have been developed to detect PIMs to assist clinicians in preventing ADRs in the elderly, such as Beers and The Screening Tool of Older Persons Prescriptions (STOPP) criteria. Beers criteria have lists 
of medicines mostly prescribed in North America that are deemed inappropriate regardless of patients underlying conditions or that are considered inappropriate for some comorbidities (Fick et al., 2003). STOPP detects PIMs with complementary information based on European prescribing patterns, in which the list of medicines is organized by physiological systems (Gallagher, O'Mahony, 2008). Both criteria and the updates have proven to be useful in epidemiological studies that address the quality of the medications prescribed for the elderly, and provide relevant information to establish treatment policies in health services (Fick et al., 2015; O'Mahony et al., 2015).

Prevalence of PIMs according to 2003 Beers criteria varied from $13 \%$ to $27 \%$ in primary care settings, nursing homes and hospitalized patients from different sample populations (Fick et al., 2003, Ryan et al., 2009, Leikola et al., 2011; Pasina et al., 2014). Using STOPP criteria PIMs were found in $29-44 \%$ of acutely ill hospitalized patients, primary care centers and nursing homes from different countries (Gallagher, O'Mahony, 2008; Cahir et al., 2010; Liu et al., 2012; Ubeda et al., 2012; Bradley et al., 2014).

In Brazil, PIMs detection in primary care centers, hospital outpatients and institutionalized older adults have been evaluated mainly by 2003 Beers criteria (Obreli Neto, Cuman, 2011; Oliveira et al., 2012; Faustino, Passarelli, Jacob-Filho, 2013; Cassoni et al., 2014). STOPP criteria have been less used to evaluate PIMs in Brazilian subjects probably because it is designed for Europe and it is more recent than Beers criteria.

We have investigated the exposure to PIMs in elderly outpatients with metabolic diseases using 2003 Beers and 2008 STOPP criteria and evaluated the relationship of the prevalence of PIMs with polypharmacy and other variables.

\section{METHODS}

\section{Study design and sample population}

A cross-sectional study was conducted to evaluate the pharmacotherapy and PIMs in elderly outpatients who attended the Metabolic Diseases Care Unit of the University Hospital (HU), University of Sao Paulo (USP), Sao Paulo, Brazil. The study protocol was approved by the Ethics Committee of the HU/USP (Protocol \# 571/05).

Elderly patients (60 or more years old), according to the Brazilian Institute of Geography and Statistics (http:// www.ibge.gov.br), with metabolic diseases (primary arterial hypertension, type 2 diabetes, and dyslipidemia) were subsequently selected from April 2010 to January 2011. Clinical data of the patients were obtained from the medical records. Patients with metabolic diseases take more than one class of medicines to regulate the metabolic status and reduce the risk for cardiovascular diseases, therefore they are more prone to have PIMs and drug-drug interactions.

The sample size $(\mathrm{n}=207)$ was calculated considering 95\% confidence level, 5\% confidence interval and the $16 \%$ of PIMs (lower rate described in Brazilian studies). Subjects prescribed with homeopathic medicines, multivitamins or topic medications were not included in this study.

\section{Pharmacotherapy and PIMs}

Medication prescriptions were obtained from the medical records and from the Pharmacy Service. Information was recorded considering the number of medications, therapeutic classes, dosages, frequencies, periods and other data. Polypharmacy was considered when the patient was prescribed with five or more medicines (Viktil et al., 2007).

PIMs were analyzed using 2003 Beers and 2008 STOPP criteria that were used because the study was carried out from April 2010 to January 2011, previously to the publication of the new versions of these criteria.

The 2003 Beers has a list of 48 drugs or classes of drugs that should not be prescribed to elderly patients in general ( $>65$ years), and a complementary list covering 20 clinical conditions and therapies that should be avoided by elderly presenting with such conditions (Fick et al., 2003). Dosage and frequencies of administration that should not be exceeded were also listed. The medicines were deemed inappropriate either because they have not proven effective, or pose unnecessary risks of adverse effects, considering the existence of safer alternatives.

The 2008 STOPP tool displays a list of 65 drugs/ therapeutic classes grouped by physiological systems (cardiovascular, respiratory, and others) (Gallagher, O'Mahony, 2008). These drugs may be inappropriate when prescribed alone, contraindicated when used concomitantly with other drugs or inadequate in specific medical conditions.

\section{Statistical Analysis}

Statistical analysis was performed using the Sigma Stat software v. 3.5 (SPSS Inc., Chicago IL). Categorical variables were compared by chi-square test. The relationship of PIMs with polypharmacy and other 
variables was evaluated by Odds Ratio (OR) with $95 \%$ Confidence Interval (CI). The level of significance was considered $\mathrm{p}<0.05$.

\section{RESULTS}

Table I presents the PIMs detected in 207 elderly outpatients, aged 60 to 96 years old, and with high prevalence of women $(62.8 \%)$. The detection of PIMs was higher using 2008 STOPP (44.4\%) when compared to that of 2003 Beers criteria $(16.0 \%, \mathrm{p}<0.001)$. Gender and age ranges did not influence the prevalence of PIMs independently of the criteria used ( $\mathrm{p}>0.05)$.

Patients were grouped in ranges of 10 years each to evaluate whether age ranges influence PIMs prevalence, but no relationship was found using both criteria. The rate of PIMs associated with polypharmacy using 2008 STOPP criteria was higher than by 2003 Beers lists $(\mathrm{p}<0.01)$.

As shown in Table II, the most commonly prescribed 2003 Beers-detected PIMs were antihypertensive vasodilators $(30.0 \%)$, such as clonidine and doxazosin, and antidepressants $(25.0 \%)$, such as fluoxetine and amitriptyline. Moreover, $65 \%$ of these PIMs had high degree of severity.

Analysis using 2008 STOPP method showed that PIMs were predominantly medicines used for treatment of cardiovascular $(73.2 \%)$ and endocrine disorders $(23.2 \%)$ (Table III). Aspirin without indication and glibenclamide for type 2 diabetes (T2D) patients were the most prescribed PIMs. Aspirin was considered PIM for patients without history of coronary, cerebral or peripheral vascular symptoms or occlusive event. Other PIMs were related to prescriptions of thiazide diuretics for patients with gout, high dose of aspirin (over $150 \mathrm{mg} /$ day) for patients with cardiovascular-related conditions, and also amitriptyline, calcium channel blockers, theophylline and diclofenac. Interestingly only aspirin and amitryptiline were detected as PIMs by both criteria.

As shown in Figure 1, age and gender were not associated with PIMs in this sample. On the other hand, patients who took more than 5 medicines (polypharmacy) had increased risk for PIMs detected by 2003 Beers $(\mathrm{OR}=4.0,95 \% \mathrm{CI}=1.2-13.8, \mathrm{p}=0.031)$. The risk was even higher when PIMs were detected by 2008 STOPP $(\mathrm{OR}=6.8,95 \% \mathrm{CI}=3.0-15.3, \mathrm{p}<0.001)$.

\section{DISCUSSION}

The 2008 STOPP method detected twice more PIMs than 2003 Beers criteria in the elderly outpatients with metabolic diseases, which did not differ from the results found in other sample populations. The 2008 STOPP criteria detected a larger number of PIMs than the 2003 Beers criteria in community-dwelling older adults and in nursing home residents from Spain (Ubeda et al., 2012; Blanco-Reina et al., 2014). In Irish long-term

TABLE I - Pharmacotherapy of elderly outpatients with metabolic diseases, n=207, Sao Paulo, SP

\begin{tabular}{llccc}
\hline Variable & & Beers & STOPP & $p$ \\
\hline Age & $60-69(77)$ years & $13.0 \%(10)$ & $42.9 \%(33)$ & $<0.01$ \\
& $70-79(85)$ years & $18.8 \%(16)$ & $43.5 \%(37)$ & $<0.01$ \\
& $\geq 80(45)$ years & $15.5 \%(7)$ & $48.9 \%(22)$ & $<0.01$ \\
& $p$ & 0.65 & 0.92 & $<0.01$ \\
\hline Gender & female (130) & $15.4 \%(20)$ & $42.3 \%(55)$ & $<0.01$ \\
& male (77) & $16.9 \%(13)$ & $48.0 \%(37)$ & 0.20 \\
& $p$ & 0.92 & 0.51 & $<0.01$ \\
\hline Pharmacotherapy & $<4$ medicines (53) & $5.7 \%(3)$ & $15.5 \%(8)$ & $<0.01$ \\
& $\geq 5$ medicines (154) & $19.5 \%(30)$ & $54.5 \%(84)$ & $<0.01$ \\
& $p$ & 0.027 & $<0.01$ & 0.52 \\
\hline PIMs & total & $16.0 \%(33)$ & $44.4 \%(92)$ & $35.7 \%(74)$ \\
& 1 per patient & $12.0 \%(25)$ & $8.7 \%(18)$ & 0.01 \\
\hline
\end{tabular}

Number of patients in parenthesis. Variables were compared by chi-square test. PIMs: potentially inappropriate medications; STOPP: Screening Tool of Older Persons' Potentially Inappropriate Prescriptions. 
TABLE II - PIMs in elderly outpatients with metabolic diseases according to Beers criteria, n=207, Sao Paulo, SP

\begin{tabular}{lccc}
\hline Medication class & Medications & Severity rating & PIMs (40) \\
\hline Antidepressant & fluoxetine & high & $15.0 \%(6)$ \\
& amitriptyline & high & $10.0 \%(4)$ \\
Anxiolytic & diazepam & high & $5.0 \%(2)$ \\
& clonazepam & high & $2.5 \%(1)$ \\
Antiarrhythmic & amiodarone & high & $2.5 \%(1)$ \\
Antihypertensive & clonidine & low & $20.0 \%(8)$ \\
& doxazosin & low & $10.0 \%(4)$ \\
Antiplatelet & methyldopa & high & $5.0 \%(2)$ \\
& aspirin & high & $5.0 \%(2)$ \\
Laxatives & ticlopidine & high & $5.0 \%(2)$ \\
NSAID & mineral oil & high & $2.5 \%(1)$ \\
Oral iron supplement & ketorolac & high & $2.5 \%(1)$ \\
Skeletal muscle relaxant & ferrous sulfate $(>325 \mathrm{mg} / \mathrm{d})$ & low & $5.0 \%(2)$ \\
& carisoprodol & high & $2.5 \%(1)$ \\
Urinary tract antispasmodic & cyclobenzaprine & high & $2.5 \%(1)$ \\
\hline
\end{tabular}

Number of PIMs in parenthesis. NSAID: non-steroidal anti-inflammatory drug; PIMs: potentially inappropriate medications.

TABLE III - PIMs in elderly outpatients with metabolic diseases according to STOPP criteria, n=207, Sao Paulo, SP

\begin{tabular}{|c|c|c|}
\hline System & Medication & PIMs (108) \\
\hline \multirow[t]{8}{*}{ Cardiovascular } & aspirin without indication & $53.7 \%(58)$ \\
\hline & $\operatorname{aspirin}(>150 \mathrm{mg} / \mathrm{d})$ & $5.6 \%(6)$ \\
\hline & aspirin + warfarin without anti-H2 or PPI & $0.9 \%(1)$ \\
\hline & amlodipine in constipated patient & $0.9 \%(1)$ \\
\hline & thiazide diuretics in patients with gout & $6.5 \%(7)$ \\
\hline & furosemide for edema without signs of $\mathrm{CHF}$ & $2.8 \%(3)$ \\
\hline & carvedilol in patient with urinary incontinence & $0.9 \%(1)$ \\
\hline & 2 beta-blockers; 2 ACE inhibitors (Duplication of pharmacological class) & $1.9 \%(2)$ \\
\hline \multirow[t]{2}{*}{ Endocrine } & glibenclamide in T2D patients & $21.3 \%(23)$ \\
\hline & propranolol in patients with hypoglycemic episode & $1.9 \%(2)$ \\
\hline Central nervous & amitriptyline and calcium channel blocker (1 patient with glaucoma and BPH) & $1.8 \%(2)$ \\
\hline Respiratory & theophylline as monotherapy for COPD & $0.9 \%(1)$ \\
\hline Skeletal muscle & diclofenac in patient with CRF and hypertension & $0.9 \%(1)$ \\
\hline
\end{tabular}

Number of PIMs in parenthesis. ACE: angiotensin converting enzyme; Anti-H2: antihistamine; BPH: benign prostate hyperplasia; CHF: cardiac heart failure; COPD: chronic obstructive pulmonary disease; CRF: chronic renal failure; PPI: proton pump inhibitor; PIMs: potentially inappropriate medications; T2D: type 2 diabetes.

care residents 2008 STOPP criteria identified a higher percentage of PIMs than the 2003 Beers list (O’Sullivan et al., 2013).

A systematic review evaluated 13 studies (12 observational studies and 1 randomized controlled trial) that investigated the prevalence of PIMs in older adults (Hill-Taylor et al., 2013). Six studies reported 2008 STOPP criteria as more sensitive than 2002 Beers criteria for PIMs detection. According to the authors, the 2008 STOPP criteria have been used to evaluate the medication 


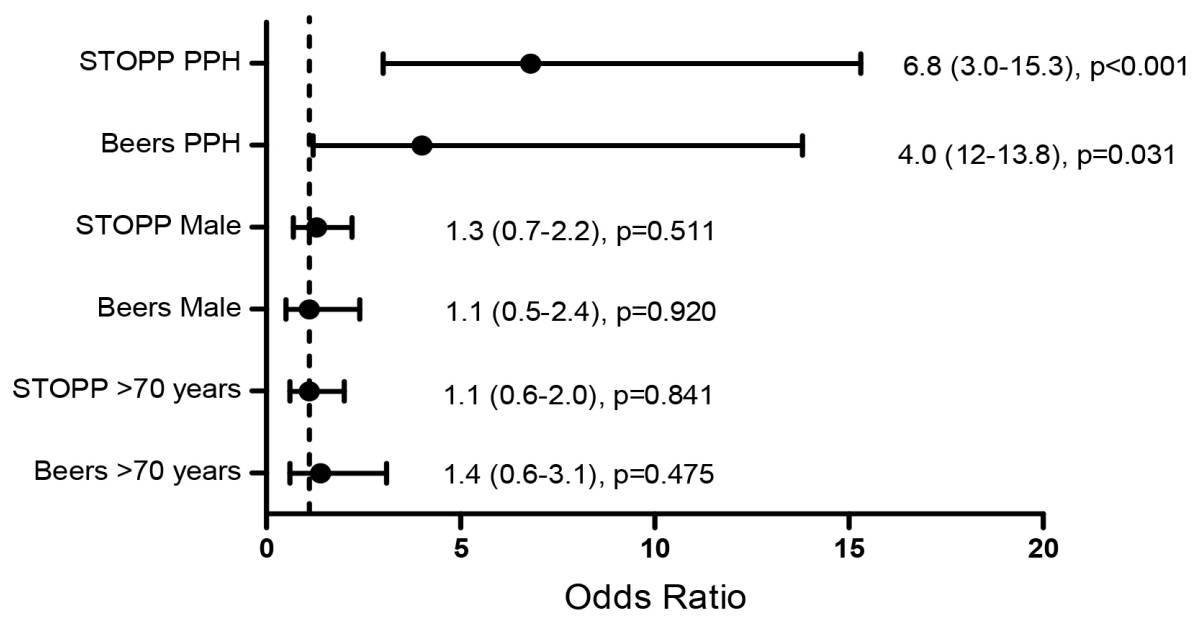

FIGURE 1 - Factors associated with PIMs in elderly outpatients according to Beers and STOPP criteria. 95\% confidence interval is shown in parenthesis. PPH: polypharmacy ( $\geq 5$ medicines); PIMs: potentially inappropriate medications.

profiles of community-dwelling, acute care and long-term care older patients in Europe, Asia and North America.

The detection of PIMs using 2003 Beers criteria in our sample was lower than that found in a Brazilian primary care setting using both 2003 and 2012 Beers criteria ( $>48.8 \%)$, probably due to different clinical and socio-demographic factors (Baldoni et al., 2014).

In this study, PIMs detected by 2003 Beers criteria were mainly antihypertensive, such as clonidine and doxazosin and antidepressants, such as fluoxetine and amitriptyline. Moreover $65 \%$ of the 40 Beers-detected PIMs had high level of severity. Other works have reported that long-acting benzodiazepines are the most frequent PIMs prescribed for North American and European older adults according to the 2003 Beers list (Stafford, Alswayan, Tenni, 2011; Gorzoni, Fabbri, Pires, 2012; Pasina et al., 2014).

The antihypertensive clonidine is an inappropriate drug for elderly people because it can potentially cause orthostatic hypotension and adverse effects in the central nervous system (CNS). Clonidine was excluded from the 2008 STOPP because it is rarely prescribed in Europe. Moreover, another study that used the PRISCUS criteria, a PIM list primarily to be used in Germany, included clonidine as PIM for exposing elderly to adverse effects such as bradycardia, hypotension, syncope, and sedation (Holt, Schmiedl, Thürmann, 2010). In Brazil, clonidine is still prescribed, although it is not indicated as initial monotherapy for blood pressure control. Thus, it is worth questioning whether clonidine should be excluded from a list of prescription drugs for seniors in Brazil.

The antihypertensive doxazosin accounted for $10 \%$ of PIMs according to the 2003 Beers in our sample. On the other hand it was disregarded as a PIM by 2008 STOPP because it is suitable for elderly patients with resistant hypertension (Gallagher, O'Mahony, 2008). A limitation of our study is that it was not possible to determine whether individuals with prescription of doxazosin have refractory hypertension to other treatments, since there was not such a level of detail in the patients' records. However, doxazosin is indicated to control symptoms of urinary obstruction in benign prostatic hyperplasia (Kirby et al., 2003), which was observed in one patient to whom doxazosin was prescribed.

The antidepressant fluoxetine is considered a PIM by the 2003 Beers criteria due to its long half-life and increased risk for excessive CNS stimulation, restlessness, and sleep disorders (Fick et al., 2003; Laroche et al., 2007).

In addition to the aforementioned medicines (clonidine, doxazosin and fluoxetine), other PIMs were detected only by 2003 Beers, including those that target the central nervous (amitriptyline, diazepam and clonazepam) and cardiovascular (methyldopa, aspirin, ticlopidine) systems. In Brazil, some of these medicines are part of the "Farmácia Dose Certa" (Right Dosage Pharmacy), a program available in the Sao Paulo State to provide some free of charge medicines in the primary care setting (Lucchetti et al., 2011). This program has significant economic and social benefit, especially for the poorest people served by the Brazilian health system. However, the prescription must be careful mainly for the elderly population in order to avoid PIMs.

In this study, the main PIM detected by 2008 STOPP criteria was aspirin without indication, including patients without history of coronary, cerebral or peripheral vascular symptoms or occlusive event. The requirements of the daily dose of aspirin were 100 to $300 \mathrm{mg}$ according to the 
disease and cardiovascular risk. However according 2008 STOPP the use of more than $150 \mathrm{mg}$ /day increases the risk of bleeding without evidence of effectiveness (Gallagher, O'Mahony, 2008).

Other studies have also reported high prevalence of prescription of non-steroid anti-inflammatory drugs (NSAIDs) detected by 2008 STOPP (Ubeda et al., 2012; Blanco-Reina et al., 2014; Vezmar Kovačević et al., 2014). Even though the international guidelines continue to indicate low-dose aspirin for reducing cardiovascular risk, this benefit may not overcome the risk of gastrointestinal bleeding in older patients (Lanas, Polo-Tomás, CasadoArroyo, 2013; Ikeda et al., 2014). In the recent review of the 2015 STOPP criteria, aspirin with concurrent high bleeding risk was one of the proposed criteria rejected by the expert panel because it could not be considered a PIM in every case (O'Mahony et al., 2015).

Glibenclamide was also pointed out by 2008 STOPP as a major PIM. It is considered unsuitable for elderly T2D patients due to the risk of prolonged hypoglycemia, a known ADR of sulfonylureas (Deusenberry et al., 2012). It is likely that the increase in prescription of glibenclamide is due to its availability by the "Farmácia Dose Certa" Program, in Sao Paulo State (Lucchetti et al., 2011).

Importantly, the majority of the PIMs detected by the 2003 Beers $(87.5 \%)$ are not included in the 2008 STOPP, because each method has a different set of rules. Amitriptyline was considered a PIM in a few cases by both criteria, while aspirin was a major PIM according to 2008 STOPP but a minor PIM by 2003 Beers. It has been suggested that the use of both 2012 Beers and 2008 STOPP may be complementary to detect PIMs in older adults (Blanco-Reina et al., 2014). However, a general guideline including these lists may not be suitable for all populations, considering that the medications approved for commercialization may differ between countries.

We did not found association of PIMs with age or gender in this sample population. Other studies have found a relationship of female and increased risk for PIMs (Faustino, Passarelli, Jacob-Filho, 2013; Baldoni et al., 2014; Cassoni et al., 2014).

Polypharmacy was associated with an increased risk of PIMs in elderly outpatients independently of the criteria used, even though polypharmacy-related PIMs were more prevalent using 2008 STOPP than 2003 Beers criteria. Polypharmacy, renal impairment and poor lipid control have been shown to be associated with drug-related problems in diabetic and dyslipidemic patients (Zaman Huri, Chai Ling, 2013), suggesting that elderly patients with metabolic diseases may be more exposed to PIMs.

Previous studies have also shown a relationship between polypharmacy and PIMs using both 2003 Beers and 2008 STOPP in different settings, such as primary care programs, community pharmacies, nursing homes, and university hospitals (Ryan et al., 2009; Cahir et al., 2010; Maio et al., 2010; Gallagher et al., 2011; Chen et al., 2012). Studies conducted in health primary care centers, outpatient clinics and long term care settings have also reported a strong association between polypharmacy and risk of PIMs in Brazil (Oliveira et al., 2012; Faustino, Passarelli, Jacob-Filho, 2013; Santos et al., 2013; Vieira de Lima et al., 2013; Cassoni et al., 2014).

The results from this study may be limited by the size sample and the version of the Beers and STOPP criteria used to detect PIMs. The criteria upgrades were based on inclusion of new licensed drugs that have been proven to be potentially inappropriate or exacerbate diseases or risk conditions for the elderly. Other drugs were excluded from the former criteria due to lack of scientific evidence or withdrawn from the market (Fick et al., 2015; O’Mahony et al., 2015). It is possible that the use of the revised criteria may reveal higher prevalence of PIMs, as it has been reported in recent Brazilian studies according to 2012 Beers (35.0-51.8\%) (Ganassin, Matos, Toffoli-Kadri, 2014; Martins et al., 2015; Oliveira et al., 2015).

We also could not evaluate the ADRs related to PIMs in this sample population, such as sedation, confusion, and lack of balance (long-acting benzodiazepines), or increased risk of orthostatic hypotension (clonidine), hyponatremia (fluoxetine), and hypoglycemia (glibenclamida). These conditions can cause dizziness and consequent fall and hip fracture, which increase the risk of thrombosis. Moreover, aspirin without indication increases the risk of ulcer and bleeding in the elderly (Fick et al., 2003; Gallagher, O’Mahony, 2008).

In conclusion, 2008 STOPP is more sensitive than 2003 Beers criteria to detect PIMs, which are strongly associated with polypharmacy in elderly outpatients with metabolic diseases. Moreover, updated criteria may be used as complementary to evaluate PIMs by healthcare practitioners in order to reduce the risk of ADRs in elderly patients.

\section{REFERENCES}

BALDONI, A.O.; AYRES, L.R., MARTINEZ, E.Z.; DEWULF, N.L.; DOS SANTOS, V.; PEREIRA L.R. Factors associated with potentially inappropriate medications use by the elderly according to Beers criteria 2003 and 2012. Int. J. Clin. Pharm., v.36, n.2, p.316-324, 2014. 
BLANCO-REINA, E.; ARIZA-ZAFRA, G.; OCAÑA-RIOLA, R.; LEÓN-ORTIZ, M. 2012 American Geriatrics Society Beers criteria: enhanced applicability for detecting potentially inappropriate medications in European older adults? A comparison with the screening tool of older person's potentially inappropriate prescriptions. J. Am. Geriatr. Soc., v.62, n.7, p.1217-1223, 2014.

BRADLEY, M.C.; MOTTERLINI, N.; PADMANABHAN, S.; CAHIR, C.; WILLIAMS, T.; FAHEY, T.; HUGHES, C.M. Potentially inappropriate prescribing among older people in the United Kingdom. BMC Geriatr., v.14, p.72, 2014.

CAHIR, C.; FAHEY, T.; TEELING, M.; TELJEUR, C.; FEELY, J.; BENNETT, K. Potentially inappropriate prescribing and cost outcomes for older people: a national population study. Br. J. Clin. Pharmacol., v.69, n.5, p.543-552, 2010.

CASSONI, T.C.; CORONA, L.P.; ROMANO-LIEBER, N.S.; SECOLI, S.R.; DUARTE, Y.A.; LEBRÃO M.L. Use of potentially inappropriate medication by the elderly in São Paulo, Brazil: SABE Study. Cad. Saúde Públ., v.30, n.8, p.1708-1720, 2014.

CHEN, L.L.; TANGIISURAN, B.; SHAFIE, A.A.; HASSALI, M.A. Evaluation of potentially inappropriate medications among older residents of Malaysian nursing homes. Int. J. Clin. Pharm., v.34, n.4, p.596-603, 2012.

DEUSENBERRY, C.M.; COLEY, K.C.; KORYTKOWSKI, M.T.; DONIHI, A.C. Hypoglycemia in hospitalized patients treated with sulfonylureas. Pharmacotherapy, v.32, n.7, p.613-617, 2012.

FAUSTINO, C.G.; PASSARELLI, M.C.; JACOB-FILHO, W. Potentially inappropriate medications among elderly Brazilian outpatients. São Paulo Med. J., v.131, n.1, p.1926, 2013.

FICK, D.M.; COOPER, J.W.; WADE, W.E.; WALLER, J.L.; MACLEAN, J.R.; BEERS, M.H. Updating the Beers criteria for potentially inappropriate medication use in older adults. Arch. Intern. Med., v.163, n.22, p.2716-2724, 2003.
FICK, D.M.; SEMLA, T.P.; BEIZER, J.; BRANDT, N.; DOMBROWSKI, R.; DUBEAU, C.E.; EISENBERG, W.; EPPLIN, J.J.; FLANAGAN, N.; GIOVANNETTI, E.; HANLON, J.; HOLLMANN, P.; LAIRD, R.; LINNEBUR, S.; SANDHU, S.; STEINMAN, M. American Geriatrics Society 2015 Updated Beers criteria for potentially inappropriate medication use in older adults. J. Am. Geriatr. Soc., v.63, n.11, p.2227-2246, 2015.

GALLAGHER, P.; LANG, P.O.; CHERUBINI, A.; TOPINKOVÁ, E.; CRUZ-JENTOFT, A.; MONTERO ERRASQUÍN, B.; MÁDLOVÁ, P.; GASPERINI, B.; BAEYENS, H.; BAEYENS, J.P.; MICHEL, J.P.; O’MAHONY, D. Prevalence of potentially inappropriate prescribing in an acutely ill population of older patients admitted to six European hospitals. Eur. J. Clin. Pharmacol., v.67, n.11, p.1175-1188, 2011.

GALLAGHER, P.; O’MAHONY, D. STOPP (Screening Tool of Older Persons' potentially inappropriate Prescriptions): application to acutely ill elderly patients and comparison with Beers' criteria. Age Ageing, v.37, n.6, p.673-679, 2008.

GANASSIN, A.R.; MATOS, V.T.G.; TOFFOLI-KADRI, M.C. Potentially inappropriate medication use in institutionalized older adults according to the Beers Criteria. Braz. J. Pharm. Sci., v.50, n.4, p.827-837, 2014.

GORZONI, M.L.; FABBRI, R.M.; PIRES, S.L. Potentially inappropriate medications in elderly. Rev. Assoc. Med. Bras., v.58, n.4, p.442-446, 2012.

HILL-TAYLOR, B.; SKETRIS, I.; HAYDEN, J.; BYRNE, S.; O’SULLIVAN, D.; CHRISTIE, R. Application of the STOPP/START criteria: a systematic review of the prevalence of potentially inappropriate prescribing in older adults, and evidence of clinical, humanistic and economic impact. J. Clin. Pharm. Ther., v.38, n.5, p.360-372, 2013.

HOLT, S.; SCHMIEDL, S.; THÜRMANN, P.A. Potentially inappropriate medications in the elderly: The PRISCUS List. Dtsch. Arztebl. Int., v.107, n.31-21, p.543-551, 2010.

IKEDA, Y.; SHIMADA, K.; TERAMOTO, T.; UCHIYAMA, S.; YAMAZAKI, T.; OIKAWA, S.; SUGAWARA, M.; ANDO, K.; MURATA, M.; YOKOYAMA, K.; ISHIZUKA, $\mathrm{N}$. Low-dose aspirin 60 years or older with atherosclerotic risk factors: a randomized clinical trial. JAMA, v.312, n.23, p.2510-2520, 2014. 
KIRBY, R.S.; ROEHRBORN, C.; BOYLE, P.; BARTSCH, G.; JARDIN, A.; CARY, M.M.; SWEENEY, M.; GROSSMAN, E.B.; PROSPECTIVE EUROPEAN DOXAZOSIN AND COMBINATION THERAPY STUDY INVESTIGATORS. Efficacy and tolerability of doxazosin and finasteride, alone or in combination, in treatment of symptomatic bening prostatic hyperplasia: the prospective European doxazosin and combination therapy (predict) trial. Urology, 61, n.1, p.119-126, 2003.

LANAS, A.; POLO-TOMÁS, M.; CASADO-ARROYO, R. The aspirin cardiovascular/gastrointestinal risk calculator - a tool to aid clinicians in practice. Aliment. Pharmacol. Ther., v.37, n.7, p.738-748, 2013.

LAROCHE, M.L.; CHARMES, J.P.; NOUAILLE, Y.; PICARD, N.; MERLE, L. Is inappropriate medication use a major cause of adverse drug reactions in the elderly? Br. J. Clin. Pharm., v.63, n.2, p.177-186, 2007.

LEIKOLA, S.; DIMITROW, M.; LYLES, A.; PITKÄLÄ, K.; AIRAKSINEN, M. Potentially inappropriate medication use among Finnish non-institutionalized people aged $\geq 65$ years: a register-based, cross-sectional, national study. Drugs Aging, v.28, n.3., p.227-236, 2011.

LIU, C.L.; PENG, L.N.; CHEN, Y.T.; LIN, M.H.; LIU, L.K.; CHEN, L.K. Potentially inappropriate prescribing (IP) for elderly medical inpatients in Taiwan: a hospital-based study. Arch. Gerontol. Geriatr., v.55, n.1, p.148-151, 2012.

LUCCHETTI, G.; LUCCHETTI, A.L.; PIRES, S.L.; GORZONI, M.L. Beers-Fick criteria and drugs available through the Farmácia Dose Certa program. São Paulo Med. J., v.129, n.1, 17-22, 2011.

MAIO, V.; DEL CANALE, S.; ABOUZAID, S.; GAP INVESTIGATORS. Using explicit criteria to evaluate the quality of prescribing in elderly Italian outpatients: a cohort study. J. Clin. Pharm. Ther, v.35, n.2, p.219-229, 2010.

MARTINS, G.A.; ACURCIO, F.A.; FRANCESCHINI, S.C.; PRIORE, S.E.; RIBEIRO, A.Q. Use of potentially inappropriate medications in the elderly in Viçosa, Minas Gerais State, Brazil: a population-based survey. Cad. Saúde Publ., v.31, n.11, p.2401-2412, 2015.
OBRELI NETO, P.R.; CUMAN, R.K.N. Potentially inappropriate medication for use in elderly and its prevalence in the SUS: evaluation of the standardized lists of drugs. Rev. Bras. Geriatr. Gerontol., v.14, n.2, 285-289, 2011.

O'CONNOR, M.N.; GALLAGHER, P.; O’MAHONY, D. Inappropriate prescribing: criteria, detection and prevention. Drugs Aging, v.29, n.6, p.437-452, 2012.

OLIVEIRA, M.G.; AMORIM, W.W.; DE JESUS, S.R.; HEINE, J.M.; COQUEIRO, H.L.; PASSOS, L.C. A comparison of the Beers and STOPP criteria for identifying the use of potentially inappropriate medications among elderly patients in primary care. J. Eval. Clin. Pract., v.21, n.2, p.320-325, 2015.

OLIVEIRA, M.G.; AMORIM, W.W.; DE JESUS, S.R.; RODRIGUES, V.A.; PASSOS, L.C. Factors associated with potentially inappropriate medication use by the elderly in the Brazilian primary care setting. Int. J. Clin. Pharm., v.34, n.4, p.626-632, 2012.

O’MAHONY, D.; O’SULLIVAN, D.; BYRNE, S.; O'CONNOR, M.N.; RYAN, C.; GALLAGHER, P. STOPP/START criteria for potentially inappropriate prescribing in older people: version 2. Age Ageing, v.44, n.2, p.213-218, 2015.

O'SULLIVAN, D.P.; O'MAHONY, D.; PARSONS, C.; HUGHES, C.; MURPHY, K.; PATTERSON, S.; BYRNE, S. A prevalence study of potentially inappropriate prescribing in Irish long-term care residents. Drugs Aging, v.30, n.1, p.39-49, 2013.

PASINA, L.; DJADE, C.D.; TETTAMANTI, M.; FRANCHI, C.; SALERNO, F.; CORRAO MARENGONI, A.; MARCUCCI, M.; MANNUCCI, P.M.; NOBILI, A.; REPOSI INVESTIGATORS. Prevalence of potentially inappropriate medications and risk of adverse clinical outcome in a cohort of hospitalized elderly patients: results from the REPOSI Study. J. Clin. Pharm. Ther., v.39, n.5, p.511-515, 2014.

PRETORIUS, R.W.; GATARIC, G.; SWEDLUND, S.K.; MILLER, J.R. Reducing the risk of adverse drug events in older adults. Am. Fam. Physic., v.87, n.5, p.331-336, 2013. 
RYAN, C.; O'MAHONY, D.; KENNEDY, J.; WEEDLE, P.; BARRY, P.; GALLAGHER, P.; BYRNE, S. Appropriate prescribing in the elderly: an investigation of two screening tools, Beers criteria considering diagnosis and independent of diagnosis and improved prescribing in the elderly tool to identify inappropriate use of medicines in the elderly in primary care in Ireland. J. Clin. Pharm. Ther., v.34, n.4, p.369-376, 2009.

SANTOS, T.R.; LIMA, D.M.; NAKATANI, A.Y.; PEREIRA, L.V.; LEAL, G.S.; AMARAL, R.G. Medicine use by the elderly in Goiania, Midwestern Brazil. Rev. Saúde Publ., v.47, n.1, p.94-103, 2013.

STAFFORD, A.C.; ALSWAYAN, M.S.; TENNI, P.C. Inappropriate prescribing in older residents of Australian care homes. J. Clin. Pharm. Ther., v.36, n.1, p.33-44, 2011.

UBEDA, A.; FERRÁNDIZ, L.; MAICAS, N.; GOMEZ, C.; BONET, M.; PERIS, J.E. Potentially inappropriate prescribing in institutionalized older patients in Spain: the STOPP-START criteria compared with the Beers criteria. Pharm. Pract. (Granada), v.10, n.2, p.83-91, 2012.
VEZMAR KOVAČEVIĆ, S.; SIMIŠIĆ, M.; STOJKOV RUDINSKI, S.; ĆULAFIĆ, M.; VUČIĆEVIĆ, K.; PROSTRAN, M.; MILJKOVIĆ, B. Potentially inappropriate prescribing in older primary care patients. PLoS One, v.9, n.4, p.e95536, 2014.

VIEIRA DE LIMA, T.J.; GARBIN, C.A.; GARBIN, A.J.; SUMIDA, D.H.; SALIBA, O. Potentially inappropriate medications used by the elderly: prevalence and risk factors in Brazilian care homes. BMC Geriatr., v.13, p.52, 2013.

VIKTIL, K.K.; BLIX, H.S.; MOGER, T.A.; REIKVAM, A. Polypharmacy as commonly defined is an indicator of limited value in the assessment of drug-related problems. Br. J. Clin. Pharmacol., v.63, p.187-195, 2007.

ZAMAN HURI, H.; CHAI LING, L. Drug-related problems in type 2 diabetes mellitus patients with dyslipidemia. $B M C$ Publ. Health, v.13, p.1192, 2013.

Received for publication on $21^{\text {st }}$ July 2015 Accepted for publication on $06^{\text {th }}$ October 2016 
